\title{
Flexible Fiberoptic Bronchoscopy Directed Interventions in Neonatal Intensive Care Unit
}

\author{
Anil Sachdev, Ritika Chhawchharia, Dhiren Gupta and Neeraj Gupta \\ From Department of Pediatrics, Sir Ganga Ram Hospital, Rajinder Nagar, New Delhi, India.
}

Correspondence to: Dr Anil Sachdev, Department of Pediatrics, Sir Ganga Ram Hospital, Rajinder Nagar, New Delhi 110 060, India. anilcriticare@gmail.com Received: April 11, 2018;

Initial review: August 20, 2018; Accepted: May 13, 2019

\begin{abstract}
Objective: To describe the utility of flexible fiberoptic bronchoscopy for the diagnosis and management in the neonatal ICU. Methods: A retrospective, medical chart review was conducted in neonates who underwent flexible fiberoptic bronchoscopy over a period of 7 years. Besides demographic data and diagnostic findings, the results of medical and/or surgical interventions done by treating neonatologist were recorded. Results: 88 bronchoscopies were performed in 83 neonates, of which 37 were done through endotracheal tube. Indications included persistent need for mechanical ventilation (32), persistent atelectasis (21), and stridor (27). Most common airway anomalies diagnosed included tracheobronchomalacia (20), laryngomalacia (18), subglottic stenosis (7), choanal atresia (4), laryngeal cleft (4), and tracheoesophageal fistula (4). Surgical interventions were undertaken in 17 cases ( 9 tracheostomies and 2 cases of slide tracheoplasty). Conclusion: Flexible fiberoptic bronchoscopy can be beneficial for the diagnosis and management of neonates with persistent or undiagnosed respiratory problems.
\end{abstract}

Keywords: Airway anomalies, Neonatal respiratory distress, Stridor.
$\mathrm{A}$ cute respiratory diseases are common neonatal conditions leading to neonatal intensive care unit (NICU) admissions. Noisy respiration with increased work of breathing, persistent need for respiratory assistance and persistent radiological opacities prompt evaluation by flexible fiberoptic bronchoscopy (FFB). To make an accurate causative diagnosis, FFB is being regularly used by pediatric pulmonologists [1]. However, information on diagnostic and therapeutic utility and safety of fiberoptic bronchoscopy in newborns is limited $[2,3]$. We present our experience with neonatal FFB over a period of 7 years. The objectives of this study were to evaluate the utility of FFB in NICU and its role in directing therapeutic interventions.

\section{METHODS}

The medical records of neonates who underwent FFB in the NICU of a tertiary care multispecialty hospital from January 2011 to June 2017 were reviewed. The data extracted from records included age, gender, gestation, birth weight, feeding problems, size and type of endotracheal tube, duration of mechanical ventilation and comorbid conditions like congenital heart disease, and post-operative status. Also data related to the indications of bronchoscopy, radiological findings, bronchoscopic findings, bronchoalveolar lavage (BAL) yield, and complications during the procedure were noted. We also noted the results of interventions (medical or surgical) done by the neonatologists post-bronchoscopy.

Bronchovideoscope (Olympus BF-XP160F) of size $2.8 \mathrm{~mm}$ with $1.2 \mathrm{~mm}$ working channel and ultrathin bronchoscope (Olympus BF-N20) of $2.2 \mathrm{~mm}$ outer diameter with no working channel were used. An informed consent was taken from the guardians prior to the procedure. The bronchoscopy team included pediatric pulmonologist, a fellow trained in assisting broncho-scopy and resuscitation, experienced nurse and a technician. Oxymetazoline $(0.025 \%)$ nasal drop was instilled in both nostrils before the procedure. Bronchoscopy was done transnasally or through endotracheal tube or laryngeal mask airway. Oxygen by simple mask was delivered continuously during transnasal bronchoscopy. All subjects were monitored using multi-parameter monitor for oxygen saturation and arrhythmia.

The anatomy and dynamics of laryngeal structures including arytenoids, epiglottis and vocal cords were studied. During the procedure, $1 \%$ lidocaine was instilled by "Spray and proceed technique" through the working channel. After negotiating the vocal cord, the subglottis 


\section{What This StUdy Adds?}

- Flexible fiberoptic bronchoscopy can be safely performed in neonatal intensive care units.

- It aids in management of persistent and unexplained neonatal respiratory problems.

and trachea and bronchi were evaluated anatomically and functionally. All along the lower airways, the bronchial mucosa and the airway pattern were studied. All procedures were recorded and stored electronically. The need for FFB was at the discretion of treating neonatologist.

\section{RESUlts}

During the study period, 83 neonates underwent bronchoscopy. The characteristics of the study subjects are described in Table I. Congenital heart disease was present in 18 cases. The indications of FFB included unresolved atelectasis (25), consolidation or persistent pulmonary infiltrates (21) and hyperinflation (6) on chest $X$-ray. Three of the children had persistent oxygen dependency and one child had stridor.

There were 88 bronchoscopic procedures in the 83 participants. In 77 of the procedures, an abnormality was detected. The abnormalities detected included tracheobronchitis (23), tracheobranchomalacia (18), laryngomalacia (17), laryngeal cleft (4) and subglottic stenosis (7). Tracheoesophageal fistula (2), abnormal tracheal rings (2) and extrinsic compression of airway (1). Eight children had multiple findings.

TABLE I Characteristics OF THE NeONATES $(N=83)$ WHO Underwent Fiberoptic FleXible Bronchoscopy

\begin{tabular}{lr}
\hline Variable & Value \\
\hline Gestational age (wk) & $37(26-41)^{*}$ \\
$<37$ weeks & $32(38.5)$ \\
$\geq 37$ weeks & $51(61.5)$ \\
Age at bronchoscopy (d) & $27.5(1-152)^{*}$ \\
Birth weight $(\mathrm{g})$ & $2660(820-3660)^{*}$ \\
$<1000$ gm & $2(2.4)$ \\
$1000-1500 \mathrm{~g}$ & $11(13.3)$ \\
$1500-2500 \mathrm{~g}$ & $21(25.3)$ \\
$>2500 \mathrm{~g}$ & $49(59)$ \\
Male sex & $64(77.1)$ \\
Route of bronchoscopy & \\
Transnasal & $51(57.9)$ \\
Endotracheal tube & $32(36.4)$ \\
Laryngeal mask airway & $5(5.7)$ \\
\hline Values in $n$ \% $\%$ or *median (range)
\end{tabular}

Values in $n(\%)$ or *median (range).
Bronchoalveolar lavage (BAL) was taken during 52 procedures. Indications for taking BAL were lung collapse (21), extubation failure (4), consolidation or pulmonary infiltrates (21), suspected aspiration (5), and airway bleed (1). Microbiological yield was obtained in $16(30.7 \%)$ BAL cultures. Multiple organisms were grown in three specimens. Organisms isolated were Acinetobacter baumannii (7), Pseudomonas aeroginosa (5), E. coli (3), Klebsiella pneumoniae (2) and Enterocccus spp. (1). Candida species were isolated in four BAL samples.

There was complete or partial resolution in 20 out of 25 cases of atelectasis within 24 hours of FFB. Table II lists the other medical and surgical interventions consequent to FFB. Radiological improvement was seen in $38(43.1 \%)$ neonates after bronchoscopy or after interventions guided by bronchoscopic findings.

The FFB procedure was well tolerated by majority of neonates $(94.3 \%)$ with no complications. Transient reversible hypoxemia $\left(\mathrm{SpO}_{2}<85 \%\right)$ was observed during 4 procedures while bleeding from nose occurred in 1 case. No active interventions were required except for discontinuing procedure temporarily. On no occasion procedure was abandoned and no death related to FFB was recorded.

\section{Discussion}

This study reports our experience of using flexible

TABLE II TREATMENT InTERVENTIONS After FiberoptiC FleXible Bronchoscopy Procedure

\begin{tabular}{lr}
\hline Intervention & Frequency, $n$ \\
\hline Medical & 36 \\
Antibiotic change & 10 \\
Addition of steroids & 4 \\
Anti-reflux measures & 22 \\
Surgical & 17 \\
Tracheostomy & 9 \\
TEF repair & 4 \\
Slide tracheoplasty & 2 \\
Laryngeal web excision & 1 \\
Feeding jejunostomy & 1 \\
\hline
\end{tabular}

TEF: tracheoesophageal fistula. 
fibreoptic bronchoscopy in neonates over the past 7 years. The indications for FFB procedure in our series were comparable to other studies [3,4]. Midulla, et al. [5] also noted that airway malacias were the most significant causes of persistent unexplained respiratory distress in the neonate. Our findings of laryngomalacia being the most common etiology for stridor on FFB was similar to a previous report [6]. Raine, et al. [7] reported a diagnostic yield of $86 \%$ with FFB; a finding similar to the $87.5 \%$ noted in the present study. In contrast, Kabra, et al. [8] in a recent audit in children in India reported a diagnostic yield of $34 \%$, but that study included children of all ages.

Bronchoalveolar lavage sample analysis can be particularly useful in directing treatment. The microbiological yield of $30.7 \%$ in the present study is lower than that reported by Terkawi, et al. [9] but higher than that reported by Yuan, et al. [10]. The differences noted can be due to antibiotic therapy, contamination or dilution of samples.

Our experience suggests that the procedure is very safe in experienced hands, as also noted in other studies $[11,12]$. FFB is a safe and useful procedure in the neonatal ICU that can help neonatologists to diagnose and manage persistent or unexplained respiratory problems in neonates.

Contributors: All authors contributed to data collection and manuscript writing. All authors approved the final version of manuscript and agree to be accountable for authenticity and integrity of the work.

Funding: None; Competing interest: None stated.

\section{REFERENCES}

1. Wood RE, Postma D. Endoscopy of the airway in infants and children. Pediatr. 1988;112:1-6.

2. Zohar DB, Sivan Y. The yield of flexible fiberoptic bronchoscopy in pediatric intensive care patients. Chest. 2004;126:1353-9.

3. Vijaysekaran D, Kalpana S, Ramachandran P, Nedunchelian K. Indications and outcome of flexible bronchoscopy in neonates. Indian J Pediatr. 2012; 79:1181-4.

4. De Blic J., Greenough A, Roberton NRC, Milner AD, eds. Bronchoscopy. In: Neonatal Respiratory Disorders London, Arnold, 1996.p.89-96.

5. Midulla F, de Blic J, Barbato A, Bush A, Eber E, Kotecha S. Flexible endoscopy of pediatric airways. Eur Resp J. 2003;22:698-708

6. Nussbaum E. Usefulness of miniature flexible fiberoptic bronchoscopy in children. Chest. 1994;106:1438-42.

7. Raine J, Warner JO. Fibreoptic bronchoscopy without general anaesthetic. Arch Dis Child. 1991;66:481-4.

8. Kabra SK, Lodha R, Ramesh P, Sarthi M. Fiberoptic bronchoscopy in children: An audit from a tertiary care center. Indian Pediatr. 2008;45:917-9.

9. Terkawi RS, Altirkawi KA, Terkawi AS, Mukhtar G, AlShamrani A. Flexible bronchoscopy in children: Utility and complications. Int J Pediatr Adolesc Med. 2016;3:18-27.

10. Yuan TM, Chen LH, Yu HM. Risk factors and outcomes for ventilator-associated pneumonia in neonatal intensive care unit patients. J Perinat Med. 2007;35:334-8.

11. Schnapf BM. Oxygen desaturation during fiberoptic bronchoscopy in pediatric patient. Chest. 1991;99:591-4.

12. Lindahl H, Rintala R, Malinen L, Leijala M, Sairanen H. Bronchoscopy during the first month of life. J Pediatr Surg. 1992;27:548-50. 